EPJ Web of Conferences 43, 02006 (2013)

DOI: $10.1051 /$ epjconf/20134302006

C Owned by the authors, published by EDP Sciences, 2013

\title{
Erratum to: Red horizontal branch stars in the Galactic field: A chemical abundance survey
}

\author{
M. Afşar ${ }^{1,2, a}$, C. Sneden² and B.-Q. For $^{3}$ \\ ${ }^{1}$ Department of Astronomy and Space Sciences, Ege University, 35100 Bornova, Izmir Turkey \\ ${ }^{2}$ Department of Astronomy and Mc Donald Observatory, The University of Texas, Austin, TX 78712, USA \\ ${ }^{3}$ ICRAR, University of Western Australia, 35 Stirling Hwy, Crawley, WA 6009, Australia
}

Original article:

EPJ Web of Conferences 43, 02003 (2013), DOI: 10.1051/epjconf/20134302003

The name of the last author should be B.-Q. For.

\footnotetext{
a e-mail: melike.afsar@ege.edu.tr
} 